\title{
Transcription of nanos-1 in Zebrafish Embryos is not Affected by Bisphenol A: Evaluated Using Quantitative Real-Time PCR
}

\author{
Bridget Babich, George Roba, Siti Sarah Safura*, Kevin Callahan, \& Edward Freeman \\ Department of Biology, St. John Fisher College, NY \\ bttps://doi.org/10.33697/ajur.2019.012
}

Students: bnb08764@sjfc.edu,gr00103@sjfc.edu,sss03429@sifc.edu*

Mentors:efreeman@sjfc.edu and kcallahan@sifc.edu

\begin{abstract}
The presence of primordial germ cells (PGCs) is crucial for proper gonad formation in zebrafish (Danio rerio). The many aspects of PGC migration that allow these cells to reach the proper location at the gonadal ridge include receptors, ligands, germ plasm components, and internal maintenance of PGCs. Any one of these factors could be affected by endocrine-disrupting chemicals (EDCs), which have been shown to alter the directed migration of these cells during early embryonic development. Based on recent research wherein the EDC bisphenol A (BPA) inhibited normal PGC migration, we have used the same dose of BPA to determine the impact of BPA on a gene central to proper germ cell migration. Zebrafish embryos were exposed to BPA, and the levels of the target gene nanos-1 were analyzed using quantitative real-time PCR (q-PCR). The target gene nanos-1 is a critically important germplasm component that allows for survival and proper migration of PGCs. The q-PCR results showed that BPA did not affect the transcription level of nanos-1 in zebrafish embryos.
\end{abstract}

\section{KEYWORDS}

Zebrafish; Zebrafish Embryos; nanos-1; Primordial Germ Cells; PGC Migration; Gonad Development; Endocrine-Disrupting Chemicals; Bisphenol A; Sex Determination

\section{INTRODUCTION}

Primordial germ cells (PGCs) are important for proper gonad development in both vertebrates and invertebrates and are wellstudied in common model organisms such as Drosophila, mice, zebrafish, and Xenopus., ${ }^{1,2}$ PGCs are originally located in the primary ectoderm and must migrate to the gonadal ridge, where they later differentiate into gametes. In humans, PGC migration occurs between embryonic weeks four and six. ${ }^{3}$ In mice, PGC migration begins on embryonic day eight, and the cells reach the gonadal ridge around embryonic day ten. ${ }^{4}$ In zebrafish, PGCs reach the gonadal ridge by 24 hours post fertilization (hpf) after using amoeboid movements to travel along the gonadal pathway to reach their final location at the gonadal ridge. ${ }^{1,5}$ However, when PGC migration is disrupted, the cells are unable to reach the gonad region, and improper gonad development occurs. ${ }^{6}$ Normal PGC migration requires several interrelated mechanisms. The first mechanism is attraction and repulsion of the cells via chemical cues from indicator cells, which bind to receptors on PGCs. ${ }^{7}$ Another mechanism that controls migration is the composition of germ plasm components dictated by maternal effect genes, which are active early in embryogenesis and allow for proper migration. ${ }^{8}$ Maternal effect genes are repressed when zygotic genes later become active. ${ }^{8,9}$ Both of these processes have been shown to play a crucial role in zebrafish PGC migration. ${ }^{1,9}$

Zebrafish are an ideal model organism for the study of PGC migration because embryos are generated in large numbers, develop quickly, and are transparent during the first 24 hpf. ${ }^{6}$ In addition, much is known about the PGC migration pathway. As stated above, PGCs follow the gonadal pathway and are led by attractants and repellents. One well-studied chemoattractant is SDF-1a. This attractant is secreted by somatic cells and binds to the CXCR4b receptor on PGCs. ${ }^{1}$ Another receptor, CXCR7, controls the distribution of SDF-1a, which polarizes PGCs and directs their migration toward attractants. ${ }^{7}$ Along with these receptor and signal proteins that control migration, many germplasm genes also play important roles in proper migration. nanos-1 is a germplasm component that serves to promote PGC migration and also ensures the survival of these cells. ${ }^{10}$ Because of its essential role in the PGC migration pathway, nanos-1 is highly conserved across species and is initially a maternal effect gene. ${ }^{10}$ This gene product is primarily present during PGC migration and again during PGC incorporation into the gonad during the first five days of development. ${ }^{10}$ In a 2001 study, when nanos- 1 was knocked-down using a morpholino, PGCs did not develop normally and were unable to migrate to the gonadal ridge. ${ }^{10}$ Rather, when the concentration of the nanos- 1 protein was decreased or diminished, PGCs migrated to the somites and head region instead, where they only survived for a couple of days. ${ }^{10}$ These results illustrate the importance of nanos-1 from both a migration and maintenance perspective of PGCs in a vertebrate model organism. 
Although morpholinos are an important tool when studying the function of specific genes, they are not useful when looking at changes in gene expression caused by factors in the natural environment. Specifically, the effects of pollutants in the environment cannot directly be studied using morpholinos. Many pollutants are used as pesticides and herbicides and have adverse effects on non-target organisms, including zebrafish. Plasticizers are a type of pollutant, and collectively, these and other chemicals fall under the broad category of endocrine-disrupting chemicals (EDCs). EDCs may mimic hormones and have the ability to disrupt a variety of hormone-regulated processes. ${ }^{11}$ In a 2001 study, the EDCs endosulfan and nonylphenol were studied to evaluate their impact on PGC migration. ${ }^{11}$ The results of this study showed that when zebrafish embryos were exposed to endosulfan, there was a decreased number of PGCs and the PGCs that were present were redistributed in the embryo. ${ }^{11}$ Similar to endosulfan, nonylphenol exposure resulted in a redistribution effect, and both EDCs evaluated in this study had estrogenic effects. ${ }^{11}$ Another study evaluated the effects of deltamethrin — a pesticide that is used to kill parasites of fish but in high doses can cause metabolic disorders as it accumulates in fish tissues. ${ }^{6}$ The results showed that deltamethrin exposure causes PGCs to have structural deformities and slowed movement through the migration pathway. ${ }^{6}$ High dose exposure to deltamethrin caused PGCs to have significant morphological changes that eliminated migration. ${ }^{6}$

Another relevant EDC is Bisphenol A (BPA), a common organic chemical found in resins and many plastics. BPA has been linked to many human diseases, such as breast cancer, diabetes, and various cardiovascular, chronic respiratory, kidney, and reproductive diseases. ${ }^{12} \mathrm{BPA}$ is commonly found in the environment, especially in bodies of water due to its ubiquitous nature and common use by manufacturers. ${ }^{13}$ Similar to endosulfan and nonylphenol, BPA mimics estrogen and disrupts normal gonad formation. ${ }^{14} \mathrm{BPA}$ is therefore considered an endocrine-disrupting chemical due to its strong estrogenic mimicry. ${ }^{14} \mathrm{~A} 2017$ study found that exposure to concentrations of BPA as low as $0.001 \mu \mathrm{M}$ during development can severely impact zebrafish reproductive health, based on analysis of morphological traits post-exposure. ${ }^{15}$ The amount of BPA in the environment varies widely among geographical regions. With some areas near water waste treatment plants (WWTP) found to range from not detectable to $1.6 \mu \mathrm{M}$ and other areas reporting maximums of $36.8 \mu \mathrm{M}$ and $45.1 \mu \mathrm{M} .16,17,18$ Marine and coastal water was also measured and showed that concentrations of BPA ranged from $0.00017 \mu \mathrm{M}$ to $0.00085 \mu \mathrm{M}$, and portable tap water was found to have a maximum BPA concentration of $5.7 \mu \mathrm{M} .{ }^{16} \mathrm{BPA}$ tends to exhibit a nonmonotonic dose-response curve-meaning that there is a nonlinear relationship between effects and doses. ${ }^{19}$ This response pattern indicates that smaller, trace BPA concentrations in aquatic environments can still have adverse effects on aquatic organisms.

In a 2013 study, zebrafish embryos were exposed to two doses of BPA, $17.5 \mu \mathrm{M}$ and $35 \mu \mathrm{M}$, during the first 24 hours of development (note that these doses were initially reported in $\mathrm{mg} / \mathrm{L}$ units but were converted here for consistency with other published work). ${ }^{5}$ In situ hybridization was used to screen for the vasa gene, a marker for PGCs, to determine how BPA affected PGC migration. The results illustrated that both doses of BPA cause PGCs to migrate to ectopic locations. ${ }^{5}$ Many of the PGCs were found anterior to the gonadal region. ${ }^{5}$ All four of the above EDCs affected PGCs in similar ways: each chemical prevented PGCs from reaching the gonadal ridge. Thus, through in situ hybridization and histological profiles, studies have shown that PGCs migrate improperly and have morphological changes in the presence of certain EDCs. However, the mechanism(s) that underlie these changes are still unknown.

When looking at migration patterns of PGCs, there are three important things to consider: the signal being sent to the cells, the receptors on the cells, and the germplasm components. Each of these could potentially be affected by EDC exposure-however, none have been studied. Therefore, in this study, zebrafish embryos were exposed to the lower of the two published doses of BPA that were shown to impair PGC migration, $17.5 \mu \mathrm{M}$ (note that we confirmed that exposure to $17.5 \mu \mathrm{M}$ BPA disrupted PGC migration in our laboratory setting, data not shown). Specifically, we sought to determine if a critical gene associated with PGC migration and maintenance (nanos-1) was impacted when migration was impaired due to BPA exposure. Using q-PCR, nanos-1 was analyzed to determine $\Delta \Delta \mathrm{Ct}$ against housekeeping genes efla and 18 s. A 2008 study found that out of eight commonly used housekeeping genes, ef1 $a$ and $18 s$ were among the most stably expressed of those eight genes, which is why we have selected them as housekeeping genes. ${ }^{20}$ As indicated above, nanos- 1 is a germplasm component found in PGCs and, based on its critical importance to normal PGC migration, is a likely target to explain impaired PGC migration with EDC exposure.

\section{METHODS AND PROCEDURES}

\section{Fish maintenance}

Zebrafish were purchased at local pet stores in Rochester, NY and allowed to acclimate to the housing system for at least two weeks. Experimentation was reviewed and approved by the Institutional Animal Care and Use Committee at St. John Fisher College (IACUC Protocol \#61). Male and female zebrafish were kept together in tanks that had a constant flow of system water. System water was maintained at $27-29^{\circ} \mathrm{C}$ with a salinity between 1400-1600 microsiemens, which was checked every other day. The $\mathrm{pH}$ level was kept between 6.9-7.4 and was measured twice per week. The fish were kept on a 14-hour light/10-hour dark 
schedule and fed twice daily. The fish were fed with live brine shrimp (Utah Red Shrimp from Artemac L.L.C) and either freezedried bloodworms (San Francisco Bay Brand) or flake food (Ocean Star International freshwater aquarium flake food).

\section{Breeding and embryo collection}

Fresh system water was added to 2-3 breeding boxes along with artificial plants. Two female fish and one male fish were added to the breeding box after being fed in the afternoon. The breeding boxes were placed in a water bath at $28{ }^{\circ} \mathrm{C}$. If embryos were present in the morning, they were removed from the breeding box and placed in a petri dish with fresh system water. Embryos that appeared unhealthy or dead were removed, and healthy embryos were kept and sorted for experimentation.

\section{Endocrine-disrupting chemical exposure}

Within an hour of fertilization, wells in a 24-well plate were filled with 5-15 embryos each. The two treatment groups were as follows: vehicle-treated (1.0 of ethanol) and BPA-treated $(17.5 \mu \mathrm{M}$ in ethanol). The embryos were allowed to grow for 24 hours at $28{ }^{\circ} \mathrm{C}$. After 24 hours, any dead embryos were removed from the wells prior to fixation for RNA extraction. If more than five embryos were dead in any single well, the well was not used as a source of embryos.

\section{RNA isolation}

Embryos were removed from wells, and each group was placed into its own sterile 1.5-mL Eppendorf tube. The water was removed, and embryos were homogenized using a manual homogenizer. To each tube, $1.0 \mathrm{~mL}$ of Tri Reagent was added and allowed to sit at room temperature for 5 minutes. After 5 minutes, $200 \mu \mathrm{L}$ of chloroform was added, and the tubes were shaken for 15 seconds, incubated at room temperature for 5 minutes, and centrifuged at 12,000 xg for 15 minutes at $4{ }^{\circ} \mathrm{C}$. Following centrifugation, the aqueous, upper layer was removed and placed into new, sterile 1.5-mL Eppendorf tubes and $500 \mu \mathrm{L}$ of isopropanol was added and allowed to incubate at room temperature for 5 minutes. The tubes were again centrifuged at $12,000 \mathrm{xg}$ for 8 minutes at $4{ }^{\circ} \mathrm{C}$. The isopropanol was removed from each tube without disturbing the RNA pellet. To each tube, $1.0 \mathrm{~mL}$ of $75 \%$ ethanol was added, and tubes were centrifuged at 7,600xg for 5 minutes at $4{ }^{\circ} \mathrm{C}$. The ethanol was removed without disturbing the RNA pellets, and tubes were then allowed to evaporate off any additional ethanol for 5 minutes. RNA pellets were then resuspended in $20 \mu \mathrm{L}$ of DEPC-water at $70{ }^{\circ} \mathrm{C}$ for 15 minutes and then stored in the freezer at $-20{ }^{\circ} \mathrm{C}$. RNA concentrations were determined using a Nanodrop instrument (NanoDrop Lite Spectrophotometer from Thermo Fisher Scientific.) The blank contained $1 \mu \mathrm{L}$ of DEPC-water. Each sample was measured using $1 \mu \mathrm{L}$ of the isolated RNA sample. RNA concentration, 260/280, and 260/230 ratio values were recorded (Table 1).

\begin{tabular}{|c|c|c|}
\hline Sample number & $\mathbf{2 6 0 / 2 8 0}$ & $\mathbf{2 6 0 / 2 3 0}$ \\
\hline 1 & 1.89 & 0.67 \\
\hline 2 & 1.80 & 1.07 \\
\hline 3 & 1.93 & 1.59 \\
\hline 4 & 1.94 & 1.00 \\
\hline 5 & 1.97 & 1.84 \\
\hline 6 & 1.94 & 0.89 \\
\hline 7 & 1.89 & 0.28 \\
\hline 8 & 1.91 & 1.34 \\
\hline 9 & 2.03 & 0.28 \\
\hline
\end{tabular}

Table 1. 260/280 and 230/260 ratios of RNA samples.

\section{cDNA generation}

RNA samples were standardized based on concentration and 260/280 values. RNA samples with 260/280 ratios between 1.80 and 2.00 were used for q-PCR (Table 1). The same amount of RNA (ng) was added to separate PCR tubes, and the volumes were brought up to $5.5 \mu \mathrm{L}$ using DEPC-water. cDNA was generated using reverse transcriptase enzyme from the Thermo Scientific RevertAid Premium First Strand cDNA Synthesis Kit (Fisher product number: ferk1622). To each tube, $0.5 \mu \mathrm{L}$ of oligo $\mathrm{dt}, 2 \mu \mathrm{l}$ of $5 \mathrm{X}$ reaction buffer, $0.5 \mu \mathrm{L}$ of Ribolock RNase inhibitor $(20 \mu \mathrm{g} / \mu \mathrm{L}), 1 \mu \mathrm{L}$ of $10 \mathrm{mM}$ dNTP mix, and $0.5 \mu \mathrm{L}$ of 
RevertAid M-Mol reverse transcriptase $(200 \mu \mathrm{g} / \mu \mathrm{L})$ was added. The samples were incubated in a thermocycler using the following protocol: 60 minutes at $42{ }^{\circ} \mathrm{C}$ and 3-5 minutes at $70^{\circ} \mathrm{C}$. Samples were then stored at $-20{ }^{\circ} \mathrm{C}$ until they underwent q-PCR.

\section{Quantitative real-time PCR}

qPCR instrument was an Applied Biosystems SteponePlus Real-Time PCR system. In a single RNase-free tube, the following was added for a $10 \mu \mathrm{L}$ master mix reaction: $5 \mu \mathrm{l}$ of $2 \mathrm{X}$ SYBR green master mix (fisher product number: ferk 0373 ), $0.3 \mu \mathrm{L}$ of forward primer, $0.3 \mu \mathrm{L}$ of reverse primer, and cDNA. The primer sets used are listed in Table 2 . All reactions were performed in 96 well plates, in triplicate. Minus RT controls were run in parallel for all primer pairs and RNA samples to monitor DNA contamination. The relative transcription of nanos- 1 in each condition was normalized to $18 S$ and ef1 a levels in the respective conditions using $\Delta \Delta$ CT method. ${ }^{21}$

\begin{tabular}{|c|c|c|}
\hline Gene Name & Forward Primer & Reverse Primer \\
\hline $18 s$ & 5'-TCGCTAGTTGGCATCGTT'TA-3' & 5'-CGGAGGTTCGAAGACGATCA-3' \\
\hline ef1 a & 5'-CTTCTCAGGCTGACTGTGC-3' & 5'-CCGCTAGCAT'TACCCTCC-3' \\
\hline nanos-1 & 5'-GAGAGCAGCATGGCTT'T'TC-3' & 5'-T'TCCAAGGCTGAAAGTCCTG-3' \\
\hline \multicolumn{2}{|r}{ Table 2. Primer sequences used in qPCR experiments. }
\end{tabular}

\section{RESULTS}

In order to ensure that the RNA samples were not degraded, $1 \%$ agarose gels stained with ethidium bromide were used to show proper banding patterns. As shown in Figure 1, the banding pattern of each sample has two bands that are located at the 28S and $18 \mathrm{~S}$ positions relative to the RNA ladder.

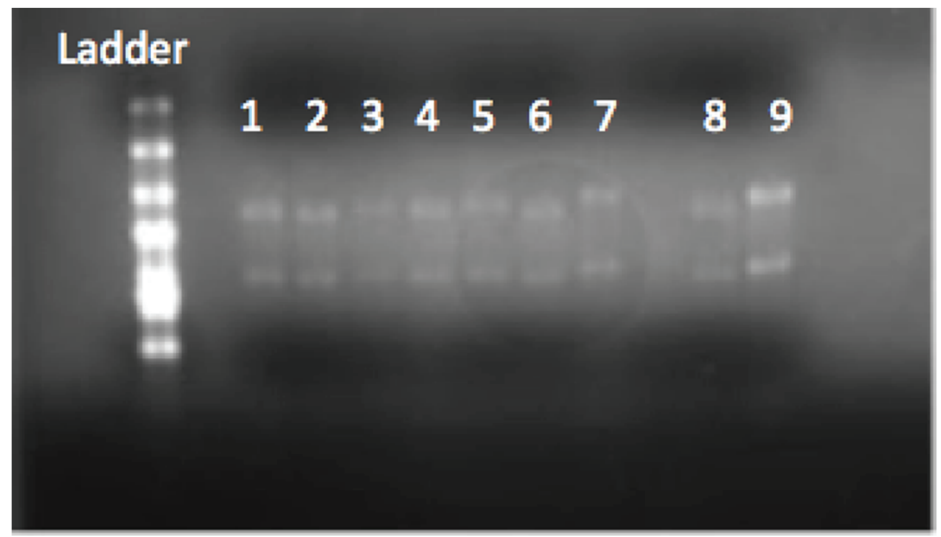

Figure 1. 1\% agarose gel run to check the integrity and quality of RNA samples prior to qPCR. RNA samples on gel represent the samples shown in Table 1.

Once purity, concentration, and stability of the sample were determined to be suitable, several samples were used for q-PCR. Data from the q-PCR was analyzed using $\Delta \Delta C$ T values (Table 3). Analysis of the $\Delta \Delta C T$ values demonstrates that nanos-1 transcription levels do not change following BPA exposure.

\begin{tabular}{|c|c|c|c|c|c|c|c|c|c|c|c|}
\hline \multicolumn{4}{|c|}{ Trial 1} & \multicolumn{4}{|c|}{ Trial 2} & \multicolumn{4}{|c|}{ Trial 3} \\
\hline Treatment & Gene & $\begin{array}{c}\text { Average } \\
\text { CT }\end{array}$ & $\overline{\Delta \Delta \mathrm{CT}}$ & Treatment & Gene & Average CT & $\overline{\Delta \Delta C T}$ & Treatment & Gene & $\begin{array}{c}\text { Average } \\
\text { CT }\end{array}$ & $\Delta \Delta \mathrm{CT}$ \\
\hline \multirow[t]{3}{*}{ Vehicle } & eft $a$ & 10.984 & \multirow[t]{3}{*}{--} & \multirow[t]{3}{*}{ Vehicle } & eft $a$ & 10.984 & \multirow[t]{3}{*}{--} & \multirow[t]{3}{*}{ Vehicle } & eft $a$ & 10.686 & \multirow[t]{3}{*}{--} \\
\hline & $18 s$ & 19.109 & & & $18 s$ & 19.109 & & & $18 s$ & 21.470 & \\
\hline & nanos1 & 26.333 & & & nanos1 & 26.333 & & & nanos1 & 23.513 & \\
\hline \multirow{3}{*}{$\begin{array}{c}17.5 \mu \mathrm{M} \\
\mathrm{BPA}\end{array}$} & eft $a$ & 11.008 & 0.690 & \multirow[t]{3}{*}{$17.5 \mu \mathrm{M} \mathrm{BPA}$} & eft $a$ & 11.122 & \multirow[t]{3}{*}{0.941} & \multirow{3}{*}{$\begin{array}{c}17.5 \mu \mathrm{M} \\
\mathrm{BPA}\end{array}$} & eft $a$ & 11.021 & 1.329 \\
\hline & $18 \mathrm{~s}$ & 18.584 & \multirow[t]{2}{*}{0.471} & & \multirow[t]{2}{*}{ nanos1 } & \multirow[t]{2}{*}{26.558} & & & $18 s$ & 21.327 & \multirow[t]{2}{*}{0.954} \\
\hline & nanos1 & 26.891 & & & & & & & nanos1 & 23.437 & \\
\hline
\end{tabular}

Table 3. Raw data from each of the three qPCR experiments. Specifically, $\Delta \Delta C$ T values of nanos-1, in relation to multiple housekeeping genes (ef1 a and $18 s)$, are provided. Each trial represents a biological replicate, and the average CT values represent three reactions for each primer set. 


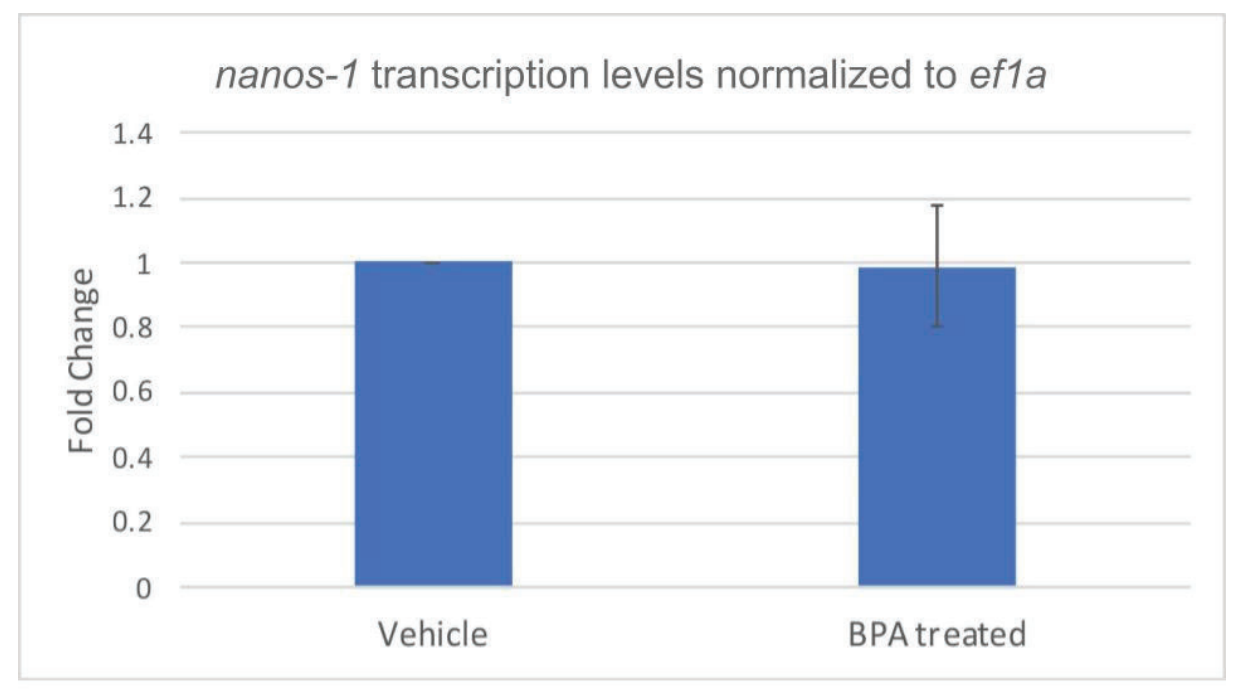

Figure 2. nanos-1 gene transcription levels, normalized to ef1 a levels, from Danio rerio embryos exposed to $17.5 \mu \mathrm{M}$ of BPA, compared to vehicle treatment. The logarithmic scale further illustrates the transcription $\mathrm{n}$ levels of nanos- 1 do not change when exposed to BPA.

As shown in Figure 2, the average $\Delta \Delta C T$ values for the three trials of nanos-1, normalized to ef1 a, are shown in a logarithmic value and only vary from the value of 1 by one-fold. ${ }^{20}$ Similar results were seen when nanos- 1 was normalized to $18 s$. (data not shown). The one-fold difference for the results illustrates that there is no significant change in transcription level of nanos-1 when PGCs are exposed to BPA.

\section{DISCUSSION}

PGCs in zebrafish are ideal cells to study when evaluating the role of endocrine-disrupting molecules in vertebrates. PGCs must travel to and incorporate into the gonad for proper development of the gonad to occur. When PGCs are exposed to BPA, they are unable to migrate correctly. The current study was performed to analyze the role of BPA on the transcription of the germplasm component nanos-1 through q-PCR. It was hypothesized that BPA would alter the transcription levels of nanos-1, thus providing information to help explain the mechanism of BPA-induced abnormal PGC migration. The hypothesis was not supported by the data, as nanos-1 RNA levels remained unchanged following BPA exposures. This result is significant because it allows other aspects of nanos-1 expression, like translation, to become the focus of future studies to understand better the mechanism of action for BPA in disrupting PGC migration. Note that our method, which involves homogenization of the embryos, does not analyze whether BPA affects nanos-1 mRNA levels in a specific, localized region—rather, it analyzes levels throughout the whole embryo. Future studies could analyze whether or not BPA exposure affects nanos-1 levels in specific regions of the embryo.

Overall, this data does not follow the hypothesis of nanos- 1 transcription levels being affected by BPA exposure in zebrafish embryos. The next step is to determine how BPA affects other aspects of PGC migration. This study indicates that other factors in PGC migration must be affected by BPA exposure. Potential targets include nanos-1 at the translational level, genes that control receptors on the germ cell receiving the migration signals, the genes that contribute to the signals being sent to PGCs, or genes that play a role in internal $\mathrm{pH}$ control of PGCs. Once the genes affected by BPA are determined using $\mathrm{q}-\mathrm{PCR}$, it would also be appropriate to determine if isoforms of $\mathrm{BPA}$, such as Bisphenol $\mathrm{F}$ or $\mathrm{S}$, also negatively affect PGC migration and if similar genes are affected. It is also possible that BPA affects the expression of these genes at the translational level. Thus it is necessary to complement qPCR with western blot analysis to determine how BPA affects the protein level of these potential targets.

In a 2006 study, the roles of SDF-1 and CXCR4a were analyzed to determine their role in PGC migration. ${ }^{2}$ SDF-1 is a ligand that binds to CXCR4a to ensure proper migration of PGCs. ${ }^{2}$ When there is a loss of function in SDF-1, PGCs are not able to able to migrate correctly. Since our results show that the transcription levels of nanos-1 are not affected by BPA, an important next study would be to determine if BPA affects the ligand-receptor relationship of SDF-1 and CXCR4a. Along with a PGC ligand and receptor possibly being affected by BPA, there is another aspect of PGCs that could be affected and cause abnormal PGC migration. Specifically, the $\mathrm{pH}$ of PGCs was analyzed to understand the role of $\mathrm{pH}$ in PGC migration. ${ }^{22} \mathrm{Ca} 15 \mathrm{~b}$, a gene that contributes to the control of the $\mathrm{pH}$ of PGCs and, subsequently, to their migration patterns, was knocked down with morpholinos. ${ }^{22}$ When there is a loss of function in Ca15b, the internal pH levels become elevated, which causes PGCs to lose their ability to travel the normal migration pathway. Another potential study, therefore, would be to consider the impact of BPA exposure on Ca15b gene expression levels. 


\section{CONCLUSIONS}

Based on recent data from Akbulut, et al., BPA exposure leads to PGC migration defects, as assessed by in situ hybridization. ${ }^{5}$ Their use of in situ hybridization with the vasa gene, a known germ cell marker, allowed them to see the varying locations of PGCs following BPA exposure. ${ }^{5}$ The majority of experimental embryos in the current study did not show clustered PGC staining,

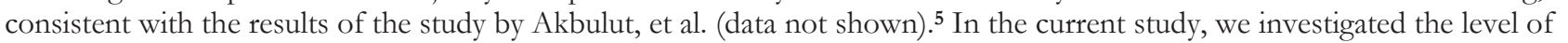
nanos-1 transcription after BPA exposure by measuring RNA levels using qPCR. These experiments were conducted to determine if this gene was affected by BPA exposure at the transcriptional level, as this could provide a novel piece of evidence for a potential mechanism by which EDCs impact PGC migration. nanos-1 is a highly conserved gene that has been shown to play a crucial role in proper PGC migration during the first 24 hpf. ${ }^{10}$ The lack of a change in nanos-1 transcription levels shown in our study indicates that nanos-1 transcription does not appear to be a target for BPA-induced disruption of PGC migration. Specifically, this is shown by the one-fold or less change in the average $\Delta \triangle \mathrm{CT}$ values for nanos-1 following BPA exposure when normalized to ef1 a and $18 s$ (18s data not shown) (Figure 2). These results suggest that because nanos-1 transcription was not affected by BPA, nanos-1 translation or other genes may be targets of this EDC. Therefore, studying the level of translation for nanos-1, as well as the overall expression of genes other than nanos-1 may help to explain the impact of BPA exposure on PGC migration.

It is well-established in the current scientific literature that BPA has adverse effects on zebrafish development. ${ }^{5,15}$ It is also known that BPA can have adverse effects on human health. ${ }^{12}$ Little is known about the mechanism by which BPA disrupts endocrine function, and this research aims to shed light on that mechanism. Zebrafish are particularly useful as a model organism for analyzing the mechanism of action of EDCs in vertebrates. Therefore, this research can shed light on the mechanism by which BPA affects both zebrafish and humans. ${ }^{23}$ Knowledge of BPA's mechanism of action is relevant to both human health and, from an ecological perspective to the health of aquatic organisms.

\section{ACKNOWLEDGMENTS}

Authors thank Jennifer Gantress, Lab Manager, for purchasing supplies and St. John Fisher College, for providing budgetary support.

\section{REFERENCES}

1. Paksa, A. and Raz, E. (2015) Zebrafish germ cells: motility and guided migration, Curr Opin Cell Biol, 36, 80-85. bttps:// doi.org/10.1016/j.ceb.2015.07.007

2. Raz, E. and Reichman-Fried, M. (2006) Attraction rules: germ cell migration in zebrafish, Curr Opin Genet Dev, 16(4), 355-359. https:// doi.org/10.1016/j.gde.2006.06.007

3. Fujimoto, T., Miyayama, Y., and Fuyuta, M. (1977) The origin, migration and fine morphology of human primordial germ cells, Anat Rec, 188(3), 315-329. bttps:/ / doi.org/10.1002/ ar.1091880305

4. Wear, H.M., McPike, M., and Watanabe, K. (2016) From primordial germ cells to primordial follicles: a review and visual representation of early ovarian development in mice, J Ovarian Res, 9:36. https:// doi.org/10.1186/s13048-016-0246-7

5. Akbulut, C., Kizil, A., and Yon, N.D. (2013) Effects of low doses of bisphenol A on primordial germ cells in zebrafish (Danio rerio) embryos and larvae, Kafkas Universitesi Veteriner Fakeiltesi Dergisi, 19(4), 647-653. https:/ / doi.org/10.9775/ kvfd.2013.8600

6. Yön, N. and Yüce, R. (2013) Effect of deltamethrin on primordial germ cells in zebrafish (Danio rerio) Embryos, Fresenius Environmental Bulletin, 22(11), 3217-3222.

7. Boldajipour, B., Mahabaleshwar, H., Kardash, E., Reichman-Fried, M., Blaser, H., Minina, S., Wilson, D., Xu, Q., and Raz, E. (2008) Control of chemokine guided cell migration by ligand sequestration, Cell,132(3), 463-473.

https:// doi.org/10.1016/j.cell.2007.12.034.

8. Weidinger, G., Stebler, J., Slanchev, K., Dumstrei, K., Wise, C., Lovell-Badge, R., Thisse, C., Thisse, B., and Raz, E. (2003) Dead end, a novel vertebrate germ plasm component, is required for zebrafish primordial germ cell migration and survival, Curr Biol, 13(16), 1429-1434.

9. Liu, W. and Collodi, P. (2010) Zebrafish dead end possesses ATPase activity that is required for primordial germ cell development, FASEB J, 24(8), 2641-2650. https:// doi.org/10.1096/fj.09-148403

10. Koprunner, M., Thisse, C., and Raz, E. (2001) A zebrafish nanos-related gene is essential for the development of primordial germ cells, Genes Dev, 15(21), 2877-2885.

11. Willey, J.B. and Krone, P.H. (2001) Effects of endosulfan and nonyphenol on the primordial germ cell population in pre-larval zebrafish embryos, Aquat Toxicol, 54,(1-2), 113-123. bttps://wmw.ncbi.nlm.nih.gov/pubmed/11451430

12. Rezg, R., El-Fazaa, S., Gharbi, N., and Mornagui, B. (2014) Bisphenol A and human chronic diseases: current evidences, possible mechanisms, and future perspectives, Environ Int, 64, 83-90. bttps:// doi.org/10.1016/j.envint.2013.12.007

13. Tsai, W. T. (2006) Human health risk on environmental exposure to bisphenol-A: a review, J Environ Sci Health C Environ Carcinog Ecotoxicol Rev, 24(2), 225-255. https:// doi.org/10.1080/10590500600936482 
14. Rhee, J. S., Kim, B. M., Lee, C. J., Yoon, Y. D., Lee, Y. M., and Lee J. S. (2011) Bisphenol A modulates expression of sex differentiation genes in the self-fertilizing fish, Kryptolebias marmoratus, Aquat Toxicol, 104(3-4), 218-229.

bttps://doi.org/10.1016/j.aquatox.2011.04.020

15. Chen, J., Saili, K.S., Liu, Y., Li, L., Zhao, Y., Bai, C., Tanguay, R.L., Dong, Q., and Huang, C. (2017) Developmental bisphenol A exposure impairs sperm function and reproduction in zebrafish. Chemosphere 169, 262-270.

https:/ / doi.org/ 10.1016/j.chemosphere.2016.11.089

16. Corrales, J., Kristofco, L.A., Steele, W.B., Yates, B.S., Breed, C.S., Williams, E.S., and Brooks, B.W. (2015) Global assessment of bisphenol A in the environment: review and analysis of its occurrence and bioaccumulation. Dose-Response 13, 1-29.

https:// doi.org/10.1177/1559325815598308

17. Fukazawa, H., Watanabe, M., Shiraishi, F., Shiraishi, H., Shiozawa, T., Matsushita, H., and Terao, Y. (2002) Formation of chlorinated derivatives of bisphenol A in waste paper recycling plants and their estrogenic activities. J Health Sciences 48, $242-249$. https://doi.org/10.1248/jhs.48.242

18. Urase, T. and Miyashita, K. (2003) Factors affecting the concentration of bisphenol A in leachates from solid waste disposal sites and its fate in treatment processes. J Mater Cycles Waste Manag, 77-82. bttp:/ / dx.doi.org/10.1007/s101630300012

19. Eladak, S., Grisin, T., Moison, D., Guerquin, M.J., N’Tumba-Byn, T., Pozzi-Gaudin, S., Benachi, A., Livera, G., RouillerFabre, V., and Habert, R. (2015) A new chapter in the bisphenol A story: bisphenol S and bisphenol F are not safe alternatives to this compound. Fertil Steril 103, 11-22. https:/ / doi.org/10.1016/j.fertnstert.2014.11.005

20. McCurley, A. T. and Callard, G. V. (2008) Characterization of housekeeping genes in zebrafish: male-female differences and effects of tissue types, developmental stage and chemical treatment, BMC Mol Biol, 9, 102-102. https://doi.org/10.1186/1471-21999-102

21. Livak, K. J. and Schmittgen, T. D. (2001) Analysis of relative gene expression data using real-time quantitative PCR and the 2- $\Delta \Delta$ CT Method. Methods, 25, 402-408. https:/ / doi.org/ 10.1006/ meth.2001.1262

22. Tarbashevich, K., Reichman-Fried, M., and Raz E. (2015) Chemokine-dependent pH elevation at the cell front sustains polarity in directionally migrating zebrafish germ cells, Curr Biol, 25(8), 1096-1103. DOI: 10.1016/j.cub.2015.02.071

23. Segner, H. (2009) Zebrafish (Danio rerio) as a model organism for investigating endocrine disruption. Comp Biochem Physiol C

Toxicol Pharmacol, 149(2), 187-195. https:// doi.org/10.1016/j.cbpc.2008.10.099

\section{ABOUT STUDENT AUTHORS}

Bridget Babich graduated with a BS in Biology from St. John Fisher College in 2015 and graduated from Physician's Assistant (PA) school in New Hampshire at the Manchester Campus of the Massachusetts College of Pharmacy and Health Sciences in 2018. She will be working in Surgical Urology at the Brigham and Women's Hospital in Boston. George Roba graduated with a BS in Biology, a BA in Psychology, and a minor in Spanish for the Health Care Professional from St. John Fisher College in 2018. He successfully completed paramedic training in May 2019 and is currently pursuing a career in healthcare. Siti Sarah Safura graduated with a BS in Biology with minors in Chemistry and Women \& Gender Studies from St. John Fisher College in 2017 and an MS in Medical Humanities from the University of Rochester in 2018. She is currently pursuing a career in medicine.

\section{PRESS SUMMARY}

This project was done to determine if nanos-1, a gene critically important in zebrafish primordial germ cell migration, is affected by BPA exposure. BPA and itanalogses are commercially used plasticizers that are known to leach out of consumer products.

Zebrafish are a commonly used model organism and are excellent models to analyze the effects of EDCs on PGC migration, a process that also occurs in humans. Proper PGC migration is necessary in vertebrates for proper gonad formation. BPA is known to disrupt PGC migration in zebrafish; however, the mechanism(s) by which this occurs is unknown. This project found that BPA does not affect nanos-1 RNA levels during PGC migration, and therefore helps rule out nanos-1 transcription as a potential target for BPA in causing abnormal PGC migration in zebrafish. 